\title{
Rate effects on Southern American English VOT
}

\author{
Paul A. Morris*
}

\begin{abstract}
This study examines the effect of speaking rate on VOT durations of initial stops in Southern American English (SAE). English is claimed to have a twoway contrast between long-lag (fortis) and short-lag (lenis) stops, but lenis stops in SAE have been shown to be produced with prevoicing rather than short-lag VOT. This study examines whether SAE lenis stops are specified for privative voice or if prevoicing is an example of contrastive emphasis. Similar to rate effects found in other languages, the data here support the conclusion that SAE does have phonologically specified privative voice in the lenis stop.
\end{abstract}

Keywords. phonetics; phonology; English; Southern American English; voice onset time (VOT)

1. Introduction. Beginning with Lisker and Abramson $(1964,1970)$, the importance of voice onset time (VOT) as a salient cue to differentiating and determining voicing categories has been well established. VOT varies by language-specific realizations of voicing categories. In languages with a two-way contrast, voicing is often realized with either prevoicing and short-lag VOT for voiced languages, as in Spanish (Lisker \& Abramson 1964) and Russian (Ringen \& Kulikov 2012), or short-lag VOT and long-lag VOT for aspirating languages, as in German (Jessen 1998). These distinctions are often attributed to the phonological feature of contrast (Table 1), so that in voicing languages, the phonological feature of contrast is [voice], but in aspirating languages the feature of contrast is [spread glottis] ([sg]) (e.g., Iverson \& Salmons 1995, Beckman, Jessen, \& Ringen 2013).

\begin{tabular}{llll} 
& $\begin{array}{l}\text { Prevoicing } \\
\text { (voiced stops) }\end{array}$ & $\begin{array}{l}\text { Short-lag VOT } \\
\text { (voiceless unaspirated) }\end{array}$ & $\begin{array}{l}\text { Long-lag VOT } \\
\text { (voiceless aspirated) }\end{array}$ \\
\hline Spanish: 2-way contrast & {$[$ voice] } & {$[\emptyset]$} & {$[\mathrm{sg}]$} \\
German: 2-way contrast & & {$[\emptyset]$} & {$[\mathrm{sg}]$} \\
Thai: 3-way contrast & [voice] & {$[\varnothing]$} & \\
\hline
\end{tabular}

Table 1. Phonological features of contrast in voicing and aspirating languages.

Besides differences in VOT due to language-specific categorical boundaries, a variety of changing articulatory and phonological factors affect VOT production and perception in specific contexts (e.g., Liberman, Cooper, Shankweiler, \& Studdert-Kennedy 1967, Miller, Green, \& Reeves 1986, Allen \& Miller 1999). Speech rate is an articulatory factor that has been shown to affect the range of VOT values of entire categories (Kessinger \& Blumstein 1996, Beckman, Helgason, McMurray, \& Ringen 2011). If a language contrasts two phonologically specified categories, as is suggested for Central Standard Swedish (Helgason \& Ringen 2008), it is expected that VOT will increase in both categories as speaking rate decreases, as has been shown for CS Swedish (Beckman et al. 2011).

\footnotetext{
* I would like to thank the participants who took part in this study, as well as Leigh Hunnicutt, Catherine Ringen, Jill Beckman, and Alexis Lee for their suggestions throughout the project. Any and all errors are mine alone. Author: Paul A. Morris, The University of Iowa (paul-a-morris@uiowa.edu).
} 
It has been argued in previous research (e.g., Lisker \& Abramson 1964, Flege 1982, Westbury 1979) that English has a two-way contrast between long-lag (fortis) and short-lag (lenis) stops. However, recent research (Hunnicutt \& Morris 2016, Jacewicz, Fox, \& Lyle 2009) indicates that in Southern American English (SAE), the lenis category of stops is produced with prevoicing rather than with short-lag VOT. This study examines the effects of speaking rate on initial stops to determine if SAE lenis stops might be specified for privative voice, or if the prevoicing noted in the literature is an example of contrastive emphasis. If SAE does contrast a phonologically specified long-lag category with a phonologically specified prevoiced category, the VOT durations in both categories should increase as speaking rate decreases.

2. English VOT variation. English is typically described as an aspirating language with a shortlag/long-lag contrast (e.g., Lisker \& Abramson 1964; Flege 1982). According to Lisker and Abramson (1964), English lenis stops are realized with either short-lag VOT or prevoicing. However, only $20 \%$ of lenis stops were produced with prevoicing, with $96 \%$ of the prevoiced tokens coming from a single speaker. Many other studies have reported English lenis VOTs similar to Lisker and Abramson (1964), with the majority of lenis stops produced with positive VOT. For example, Suomi (1980), Zue (1976), Kewley-Port (1982), and Klatt (1975) all reported exclusively positive VOT data for lenis stops (see Table 2 for an overview of the reported percentages of prevoiced English lenis stops). However, other researchers have reported variation in the realization of English lenis stops. Westbury (1979), for example, reports that across all places of articulation, $57 \%$ of utterance-initial lenis stops were produced with prevoicing. Flege (1982) also reported a high percentage (59\%) of prevoiced lenis tokens, though the experiment exclusively examined bilabial stops. Lorge (1967, as cited in Docherty 1992) reports that $41 \%$ of alveolar stops in initial position were prevoiced, but none of the bilabial stops were reported to be produced with prevoicing. Dmitrieva, Llanos, Shultz, and Francis (2015) also report that $31 \%$ of utterance-initial bilabial lenis stops were produced with negative VOT.

In a study of Southern American English spoken in Mississippi and Alabama, $77.8 \%$ of word-initial lenis tokens were produced with prevoicing (Hunnicutt \& Morris 2016). Though variation in the realization of English lenis stops as prevoiced or short-lag has been identified in other studies, the results reported in Hunnicutt \& Morris (2016) exceed previously reported variation. Rather, the data for SAE were comparable to data reported for Dutch, which is considered a true voice language, in which $75 \%$ of initial lenis stops were reported as prevoiced (van Alphen \& Smits 2004). It should also be noted that participants in the study by Flege (1982) were recruited in Alabama (SAE) and the Westbury (1979) study occurred in Texas.

\begin{tabular}{ll}
$\%$ & Study \\
\hline $0 \%$ & Suomi (1980) \\
$0 \%$ & Zue (1976) \\
$0 \%$ & Kewley-Port (1982) \\
$0 \%$ & Klatt (1975) \\
$0 \%-$ bilabial, 41\%- alveolar & Lorge (1967) \\
$20 \%$ & Lisker \& Abramson (1964) \\
$31 \%-$ bilabial & Dmitrieva et al. (2015) \\
$57 \%$ & Westbury (1979) \\
$59 \%-$ bilabial & Flege (1982) \\
$77.8 \%$ & Hunnicutt \& Morris (2016) \\
\hline
\end{tabular}

Table 2. Percentage of reported prevoiced English lenis stops. 
Additionally, considerable differences in voicing were found between speakers from Wisconsin and North Carolina (Jacewicz et al. 2009). North Carolina speakers produced considerably more voicing, with $73 \%$ of bilabial lenis tokens voiced throughout the entire closure and an average of $92 \%$ of the closure voiced. For Wisconsin speakers, only $24 \%$ of the lenis tokens were voiced through the entire closure with an average of $67 \%$ of the closure voiced.

3. Rate Effects. Previous research into the effect of speaking rate on VOT durations (e.g., Miller, Green, \& Reeves 1986, Pind 1995, Allen \& Miller 1999) show that in word-initial stop contrasts, VOT increases in the phonologically specified category as speaking rate decreases, while the unspecified category exhibits little change. Thus, in languages which contrast prevoiced stops with short-lag stops, such as Spanish (Table 3), prevoicing increases in slower speech and decreases in faster speech while short-lag VOT shows little difference. In languages which contrast short-lag stops with long-lag stops, such as German, VOT in long-lag stops increases in slow speech, with short-lag stops again remaining unchanged.

In rate effects studies on English, lenis stops have been found to be produced with shortlag VOT regardless of speaking rate. Magloire and Green (1999) found reliable but small differences in the VOT of lenis stops as an effect of rate condition, but those effects were for positive VOT (see Table 3). Aspirated stops, however, showed significantly more variation in VOT as a result of speaking rate. Similarly, Kessinger and Blumstein (1996) found that the VOT in English lenis stops remained stable across speaking rate, but that fortis stop VOT varied significantly as a result of speaking rate.

\begin{tabular}{lllll} 
& & Fast & Normal & Slow \\
\hline Spanish (monolingual) & /b/ & -45.8 & -62.1 & -69.2 \\
& /p/ & 12.4 & 19.4 & 25.9 \\
\hline English (monolingual) & $/ \mathrm{b} /$ & 12.6 & 20.3 & 18.1 \\
& $\mathrm{/p} /$ & 31.5 & 51.7 & 58.4 \\
\hline
\end{tabular}

Table 3. Rate effects on VOT for monolingual Spanish bilabials (Magloire \& Green 1999).

In languages that contrast two phonologically specified categories, as in the long-lag fortis and prevoiced lenis category contrast in Swedish (Helgason \& Ringen 2008), it would therefore be expected that VOT in both categories would increase as speaking rate decreased. Beckman et al. (2011) tested this for Swedish and found that at a slow speaking rate, the duration of prevoicing increased in lenis stops, just as the long-lag VOT increased in fortis stops (Table 4). If SAE does contrast a phonologically specified aspirated category with a phonologically specified voiced category, the VOT durations in both categories are expected to increase as speaking rate decreases.

\begin{tabular}{|c|c|c|c|}
\hline Kessinger \& Blumstein (1997): & Prevoicing & Short-lag VOT & Long-lag VOT \\
\hline French (2-way contrast) & increases & unaffected & \\
\hline German (2-way contrast) & & unaffected & increases \\
\hline Thai (3-way contrast) & increases & unaffected & increases \\
\hline \multicolumn{4}{|l|}{ Beckman et al. (2011): } \\
\hline Swedish (2-way contrast) & increases & & increases \\
\hline
\end{tabular}


Table 4. Effects of speaking rate on voicing categories in French, German, Thai, and Swedish.

4. Methods. In this study 14 participants living in Mississippi were recorded. 12 were born and raised in Mississippi and 2 were born in Alabama and had been living in Mississippi for over 10 years. The participants were monolingual speakers of English, 9 males and 5 females. Their ages ranged from 19 to 50. The recordings took place in central Mississippi.

The participants read a list of 200 English words in the carrier phrase 'I told them about

two yesterday'. Participants said the word list twice and were instructed to read each repetition at different speeds; the stimuli were presented in the same order for both readings. For the slow condition, they were instructed to say each carrier phrase and word slowly, as if trying to explain something very clearly. For the fast condition, they were instructed to say each phrase quickly, as if trying to tell something to someone who was leaving the room, but without losing accuracy. The list contained 60 stop-initial target words presented in a randomized order. There were 30 word-initial fortis stops (bilabial $=10$, alveolar $=10$, velar $=10$ ) and 30 word-initial lenis stops (bilabial $=10$, alveolar $=10$, velar $=10$ ). The majority of stimuli were voicing minimal pairs (27 of the 30 pairs), with a few near-minimal pairs. Target words were monosyllabic and were balanced for vowels following target stops.

Data were recorded with a Marantz PMD661 handheld solid-state recorder and a headmounted unidirectional microphone (Shure WH30XLR) positioned to the side approximately 3 $\mathrm{cm}$ from the subject's mouth. The data were sampled at $44100 \mathrm{~Hz}$. The recordings took place in a quiet, isolated room. The data were analyzed in Praat (Boersma \& Weenink 2017). Negative VOT was measured from the onset of voicing to the stop release. Positive VOT was measured from the stop release to the onset of voicing periodicity, as identified by the onset of the second formant in the following vowel. Word duration was measured from the stop closure to the end of the word-final phoneme. The duration of the target words was measured as an indication of speaking rate. Word duration was measured from the end of the preceding word to the end of the target word. Tokens with unnaturally long pauses between the preceding word and target word and distorted recordings were excluded from analysis. To maintain consistency across stop categories and rate conditions, if a token was excluded, it and the accompanying minimal pair word were excluded from both rate conditions, so that the set of four words from the speaker, the minimal pair in both the fast and slow condition, was excluded. A total of 96 words (24 sets of words) were excluded from analysis. VOT measurements were taken from a waveform with a spectrogram for reference.

5. Results. For lenis tokens, $95.5 \%$ were produced with prevoicing; $97.5 \%$ of lenis stops in the fast condition and $93.2 \%$ in the slow condition were prevoiced (Table 5). Across places of articulation, $95.7 \%$ of bilabial, $94.7 \%$ of alveolar, and $96.4 \%$ of velar lenis stops were prevoiced.

\begin{tabular}{lllll} 
Rate & Bilabial & Alveolar & Velar & TOTAL \\
\hline Slow & $92.9 \%$ & $91.3 \%$ & $95 \%$ & $93.2 \%$ \\
Fast & $97.8 \%$ & $97.8 \%$ & $97.6 \%$ & $97.5 \%$ \\
\hline
\end{tabular}

Table 5. Percentage of prevoiced word-initial lenis stops in the present study.

There was a large difference between the VOT of fortis stops $(\mathrm{M}=73.1 \mathrm{~ms})$ and lenis stops produced with prevoicing $(\mathrm{M}=-92 \mathrm{~ms})$. Overall, negative VOT in prevoiced lenis stops and positive VOT in fortis stops increased in the slow rate condition, compared to the fast rate condition (see Table 6). 


\begin{tabular}{lll} 
Stop Type & Fast & Slow \\
\hline Lenis: Prevoiced & $-71.7 \mathrm{~ms} \mathrm{(11.7)}$ & $-104.2 \mathrm{~ms} \mathrm{(20.6)}$ \\
Fortis: Long-lag & $63.8 \mathrm{~ms}(11)$ & $89.9 \mathrm{~ms}(15)$ \\
\hline
\end{tabular}

Table 6. Mean VOT and standard deviation of prevoiced lenis and fortis stops by rate condition. Due to the low occurrence of lenis stops with positive VOT, only prevoiced lenis stops were included in the VOT analyses ${ }^{1}$. The VOT of prevoiced and short-lag lenis stops and long-lag fortis stops are shown in Figure 1.

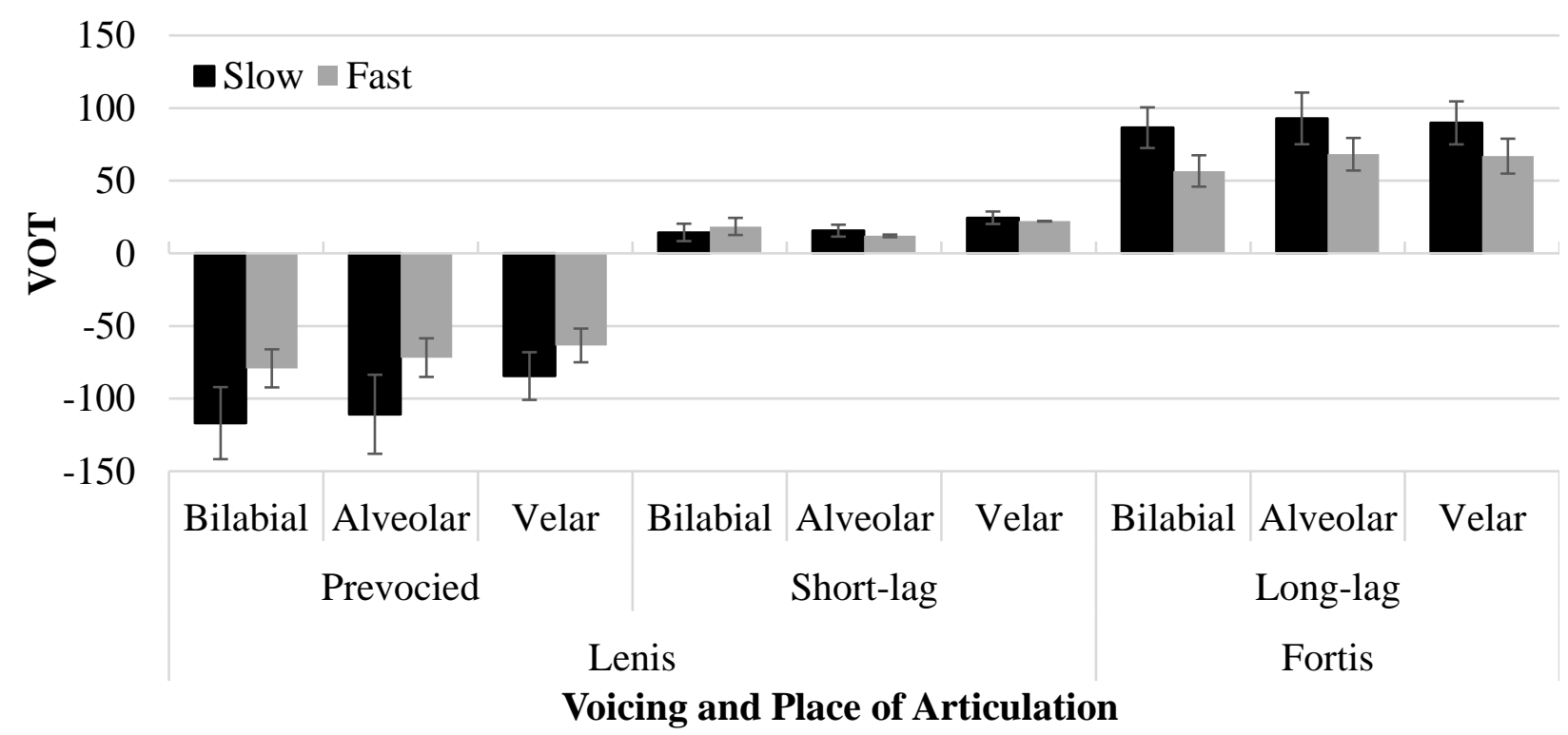

Figure 1. Effect of speaking rate on VOT of lenis prevoiced, lenis, short-lag, and fortis stops by place of articulation.

The mean voicing duration and standard deviations for utterance-initial stops by place of articulation are given in Table 7.

\begin{tabular}{llll} 
Lenis: Prevoiced & Bilabial & Alveolar & Velar \\
\hline Slow & $-116.9 \mathrm{~ms} \mathrm{(24.8)}$ & $-110.8 \mathrm{~ms} \mathrm{(27.2)}$ & $-84.5 \mathrm{~ms} \mathrm{(16.4)}$ \\
Fast & $-79.2 \mathrm{~ms} \mathrm{(13.1)}$ & $-71.8 \mathrm{~ms}(13.3)$ & $-63.4 \mathrm{~ms} \mathrm{(11.6)}$ \\
\hline Fortis & Bilabial & Alveolar & Velar \\
\hline Slow & $86.5 \mathrm{~ms}(14.0)$ & $92.9 \mathrm{~ms}(17.8)$ & $89.8 \mathrm{~ms}(14.8)$ \\
Fast & $56.7 \mathrm{~ms} \mathrm{(10.8)}$ & $68.2 \mathrm{~ms} \mathrm{(11.2)}$ & $66.9 \mathrm{~ms} \mathrm{(12.0)}$ \\
\hline
\end{tabular}

Table 7. Mean VOT and standard deviation of prevoiced lenis and fortis stops by place of articulation as a function of speaking rate.

\footnotetext{
${ }^{1}$ The mean VOT of short-lag lenis stops was $19.2 \mathrm{~ms}$. Only four participants (out of 14) produced any of the lenis stops with positive VOT. There was no significant difference in the VOT of short-lag lenis between the speaking rate conditions $(\mathrm{t}(3)=.902, \mathrm{p}=.434)$ : slow $\mathrm{M}=19.5 \mathrm{~ms}(\mathrm{SD}=5.5)$; fast $\mathrm{M}=18.7 \mathrm{~ms}(\mathrm{SD}=5.5)$ ). Mean VOT across places of articulation by rate condition were as follows:

bilabials: $\quad$ slow $\mathrm{M}=14.4 \mathrm{~ms}(6), \quad$ fast $\mathrm{M}=18.5 \mathrm{~ms}$ (5.9)

alveolars: $\quad$ slow $\mathrm{M}=15.6 \mathrm{~ms}(4.1), \quad$ fast $\mathrm{M}=12.0 \mathrm{~ms}(.9)$

velars:

slow $\mathrm{M}=24.5 \mathrm{~ms}(4.3)$, fast $\mathrm{M}=22.1 \mathrm{~ms}(.2)$
} 
To determine if rate manipulation affected speaking rates, a repeated measures ANOVA examined the effects of rate condition (slow/fast) and stop category (fortis/lenis) on word duration. Crucially, there was a significant difference in word duration by rate condition $(F(1,13)=133.3$, $\mathrm{p}<0.001 *)$, but no interaction between speaking rate and stop type $(\mathrm{p}=0.439)$. Words were spoken at an average of $401.3 \mathrm{~ms}(\mathrm{SD}=80.4)$ in fast speech and $562.2 \mathrm{~ms}(\mathrm{SD}=116.3)$ in slow speech. Paired t-tests were conducted to determine if rate condition affected VOT and confirmed a significant difference $\left(\mathrm{t}(13)=9.214, \mathrm{p}<0.001^{*}\right)$ in the VOT of lenis stops between the fast $(\mathrm{M}=$ $-71.7 \mathrm{~ms} ; \mathrm{SD}=11.7)$ and slow conditions $(\mathrm{M}=-104.2 \mathrm{~ms} ; \mathrm{SD}=20.6)$ and fortis stops $(\mathrm{t}(13)=$ $-8.754, \mathrm{p}<.001 *)$ in the fast $(\mathrm{M}=63.8 \mathrm{~ms} ; \mathrm{SD}=11)$ and slow conditions $(\mathrm{M}=89.9 \mathrm{~ms} ; \mathrm{SD}=15.1)$ (Figure 2).

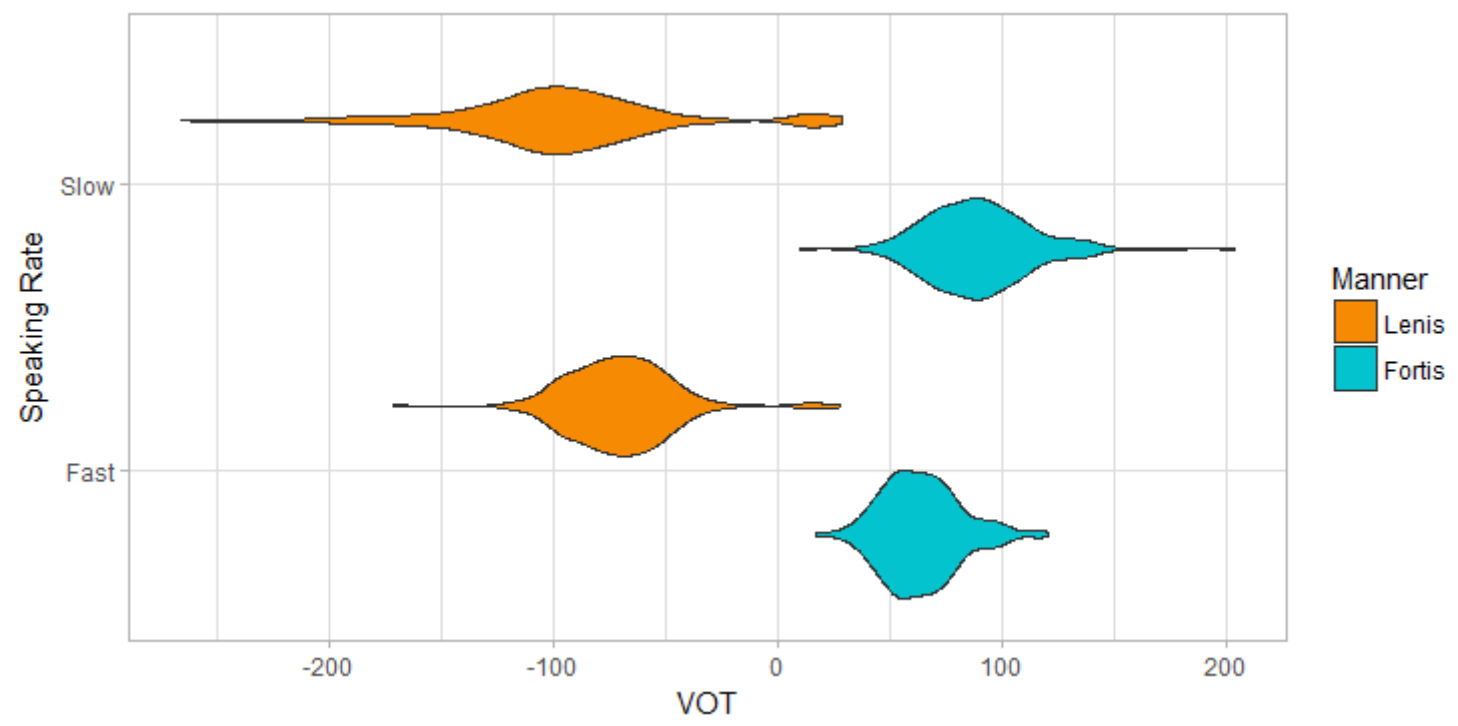

Figure 2. Distribution of VOT by speaking rate condition

A final analysis examined the continuous effect of speaking rate and VOT. Figure 3 shows the relationship between word duration and VOT across both conditions.

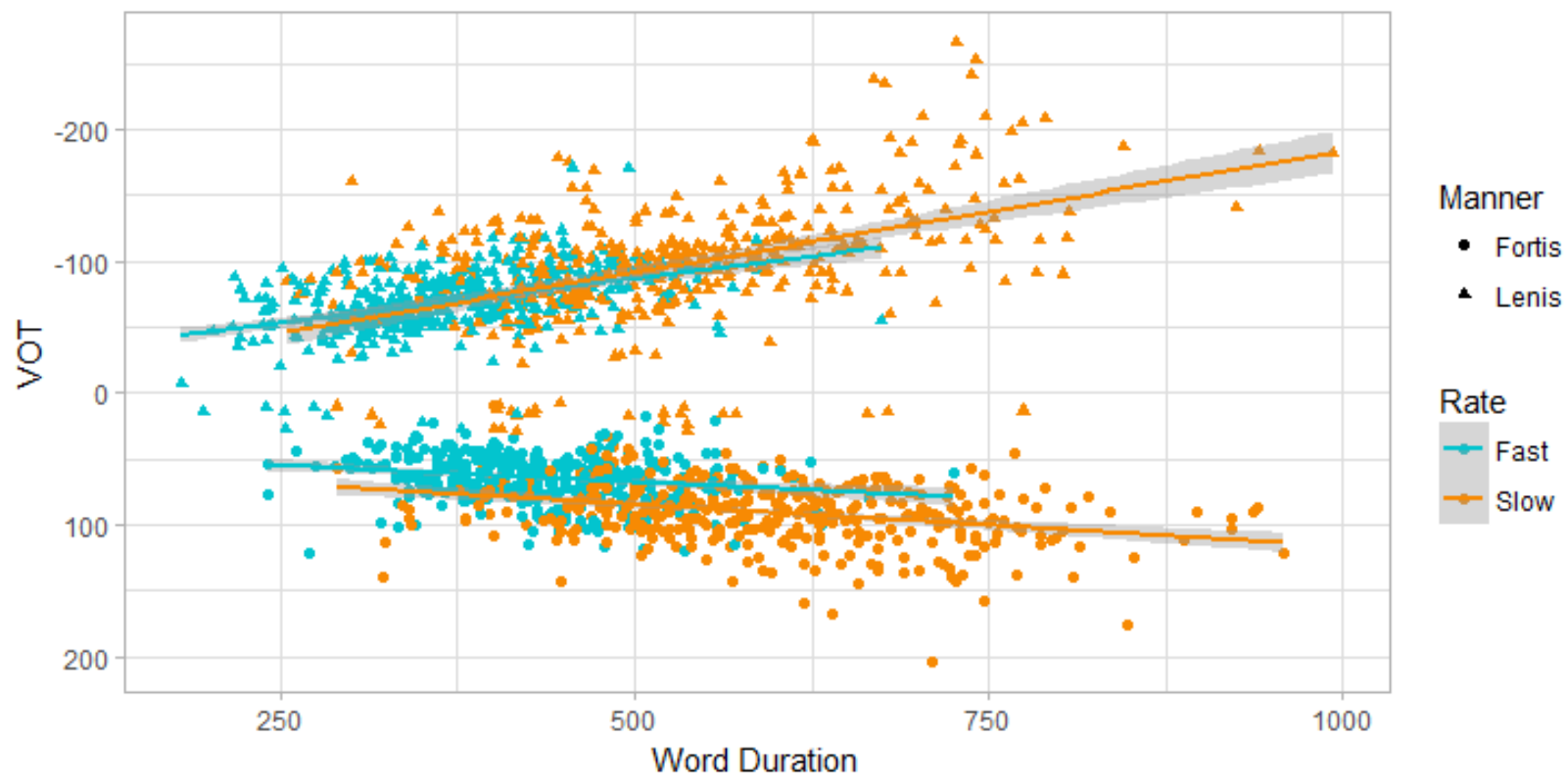

Figure 3. Relationship between word duration and VOT. 
Hierarchical linear regression analyses were conducted to examine the relationship between speaking rate and word duration with VOT for both stop categories. The first model examined lenis stops. To account for subject variance, 13 subject codes were added to the first step, which accounted for $18 \%$ of the variance $($ Fchange $(13,759)=13.1, \mathrm{p}<.001 *)$. In the second step, word duration accounted for an additional $31 \%$ of the variance $(\operatorname{Fchange}(1,758)=472.1, \mathrm{p}<.001 *)$. For lenis stops, word duration showed a negative relationship with VOT; negative VOT increased by about $.13 \mathrm{~ms}$ for each $\mathrm{ms}$ of word duration with a difference of about $12.8 \mathrm{~ms}$ between the two conditions. On the third step, rate condition accounted for an additional $2 \%$ of variance $($ Fchange $(1,757)=31, \mathrm{p}<.001 *)$. After entry of rate condition at step 3 , the total variance explained by the model as a whole was $53 \%$.

The same analysis was repeated to examine fortis stops. In the first step, subjects accounted for $23 \%$ of the variance $($ Fchange $(13,760)=17.6, \mathrm{p}<.001 *)$. In the second step, an additional $23 \%$ of the variance was accounted for by word duration (Fchange $(1,759)=331.1$, $\left.\mathrm{p}<.001^{*}\right)$. For fortis stops, word duration had a positive relationship with VOT; as words lengthened, VOT also lengthened by about $.05 \mathrm{~ms}$ for each $\mathrm{ms}$ of word duration with a difference of about $18 \mathrm{~ms}$ between the two conditions. In the third step, rate condition accounted for an additional $7 \%$ of the variance (Fchange $(1,758)=121, \mathrm{p}<.001 *)$. After entry of rate condition at step 3 , the total variance explained by the model as a whole was $54 \%$.

6. Discussion. The results illustrate that lenis stops have deeper slopes for voicing and word duration than do fortis stops. The findings on prevoiced lenis stops in this study are consistent with what has been reported on prevoicing in studies on Spanish, French, and Swedish (Table 8). Likewise, fortis stops were produced with comparable VOT as reported in other studies in English (Table 8).

\begin{tabular}{lllll} 
Language & Stop Type & Fast & Slow & Difference \\
\hline Spanish (Magloire \& Greene 1999) & Prevoiced & -45.8 & -69.2 & 23.4 \\
French (Kessinger \& Blumstein 1997) & Prevoiced & -82.5 & -110 & 27.5 \\
English (Magloire \& Greene 1999) & Long-lag & 31.5 & 58.4 & 26.9 \\
English (Kessinger \& Blumstein 1997) & Long-lag & 79 & 107.5 & 28.5 \\
English (Allen \& Miller 1999) & Long-lag & 48.6 & 78.3 & 29.7 \\
\hline Swedish (Beckman et al. 2011) & Prevoiced & -78.5 & -107.9 & 29.4 \\
& Long-lag & 55.8 & 74.5 & 18.7 \\
\hline Southern American English (present study) & Prevoiced & -71.7 & -104.2 & 32.5 \\
& Long-lag & 63.8 & 89.9 & 26.1 \\
\hline
\end{tabular}

Table 8. Reported mean VOT as a function of speaking rate from multiple studies compared to the present study.

The results showed a similar relationship in the two rate conditions between word duration and VOT among lenis and fortis stops. The data indicate that word duration had a significant effect on the relationship between speaking rate and VOT. It appears that the relationship between speaking rate and VOT is slightly stronger for lenis stops than for fortis stops, as prevoicing was affected more by word duration than was positive VOT. The slopes between prevoiced and 
long-lag VOT in this study differ somewhat from what has been found in other rate effect studies. For fortis stops in this study, there was a slope of .05ms VOT/ms word length. However, in the study by Magloire and Green (1999), English had a slope of .27ms VOT/ms word length, Pind (1995) reported a slope of .15ms VOT/ms word length for Icelandic aspirated stops, and Beckman et al. (2011) reported a slope of .10 ms VOT/ms word length for aspirated Swedish stops. There was a slope of $-.13 \mathrm{~ms}$ VOT/ms word length for lenis stops in this study, compared to a slope of $-.45 \mathrm{~ms}$ VOT/ms for Spanish prevoiced stops (Magloire \& Green 1999) and -.27ms VOT/ms for Swedish prevoiced stops (Beckman et al. 2011).

The results from studies examining languages with two-way contrasts show movement of the marked category of about $25-30 \mathrm{~ms}$ as a function of speaking rate. In the present study, the VOT of prevoiced stops was found to move $-32.5 \mathrm{~ms}$ and $+26.1 \mathrm{~ms}$ for long-lag stops. The movement away from 0 for each type of stop (lenis and fortis) is consistent for what has been previously reported for languages with only one marked category (i.e., as found for either voiced or aspirated stops). However, the $58.6 \mathrm{~ms}$ net gain of contrast is far more than what is reported for languages in which a single marked category is affected by speech rate but is in line with the $48.1 \mathrm{~ms}$ net gain between prevoiced and long-lag VOT reported for Swedish (Beckman et al. 2011).

7. Conclusion. The data presented here for Southern American English show a considerable number of prevoiced lenis stops, which far exceeds what has been reported for prevoiced lenis stops in other studies of English. Crucially, though, fortis stops were also produced with longlag VOT, similar to other varieties of English. While most studies on languages with two-way contrasts have found asymmetrical effects of speaking rate on VOT, the question remains as to how to account for the symmetrical effects found in this study.

One possible account is that the symmetrical effects on VOT in this study are the results of a need to contrast voicing categories. However, the VOT in SAE fortis stops is comparable to that found in other studies on English and shows a similar increase in VOT as a function of speaking rate. Thus, the over-specification of the voicing contrast resulting from the prevoicing of lenis stops may be a by-product of production, as is suggested for Swedish by Beckman et al. (2011), as opposed to the need to hyperarticulate to discriminate voicing contrasts.

If these effects are the result of the phonetic properties of the stops or a by-product of articulation, it might indicate that speakers of SAE are aiming to voice lenis stops and aspirate fortis stops. Prior research has shown that rate effects can be used as an indicator of the presence of active features in a phonological contrast. The results here show that speaking rate does have a significant effect not only on fortis stops in SAE, but also on lenis stops. A preliminary comparison can be made between the results for Southern American English and the results found in Central Standard Swedish by Helgason and Ringen (2008). They found that Swedish has both a prevoiced lenis series of stops and an aspirated fortis series of stops. A follow-up study on Swedish also confirmed that the VOT of prevoiced lenis stops and long-lag fortis stops were both effected by speech rate (Beckman et al. 2011). Beckman et al. (2011) conclude from this data that in Swedish, both [voice] and [spread glottis] are active. The data here show a similar spread between a fortis long-lag category of stops and a prevoiced lenis category of stops as well as rate effects on VOT for both categories. These results suggest that [voice] and [spread glottis] are also active in Southern American English. 


\section{References}

Allen, J. Sean, and Joanne L. Miller. 1999. Effects of syllable-initial voicing and speaking rate on the temporal characteristics of monosyllabic words. Journal of the Acoustical Society of America 106(4). 2031-2039. https://doi.org/10.1121/1.427949.

Beckman, Jill, Pétur Helgason, Bob McMurray, and Catherine Ringen. 2011. Rate effects on Swedish VOT: Evidence for phonological overspecification. Journal of Phonetics 39. 39-49. https://doi.org/10.1016/j.wocn.2010.11.001.

Beckman, Jill, Michael Jessen, and Catherine Ringen. 2013. Empirical evidence for laryngeal features: aspirating vs. true voice languages. Journal of Linguistics 49. 259-284. https://doi.org/10.1017/S0022226712000424.

Boersma, Paul, and David Weenink. 2017. Praat: doing phonetics by computer [Computer program] (Version 6.0.29). http://www.praat.org/.

Dmitrieva, Olga, Fernando Llanos, Amanda A. Shultz, and Alexander L. Francis. 2015. Phonological status, not voice onset time, determines the acoustic realization of onset f0 as a secondary voicing cue in Spanish and English. Journal of Phonetics 49. 77-95. https://doi.org/10.1016/j.wocn.2014.12.005.

Docherty, Gerard. 1992. The timing of voicing in British English obstruents. Berlin: Foris.

Flege, James E. 1982. Laryngeal timing and phonation onset in utterance initial English stops. Journal of Phonetics 10(2). 177-192. http://psycnet.apa.org/record/1982-32342-001.

Helgason, Pétur, and Catherine Ringen. 2008. Voicing and aspiration in Swedish stops. Journal of Phonetics 36. 607-628. https://doi.org/10.1016/j.wocn.2008.02.003.

Hunnicutt, Leigh, and Paul A. Morris. 2016. Pre-voicing and aspiration in Southern American English. In Sunghye Cho (Ed.), University of Pennsylvania working papers in linguistics 22(1). 215-224. https://repository.upenn.edu/pwpl/vol22/iss1/24.

Iverson, Gregory K., and Joseph C. Salmons. 1995. Aspiration and laryngeal representation in Germanic. Phonology 12. 369-396. https://doi.org/10.1017/S0952675700002566.

Jacewicz, Ewa, Robert Fox, and Samantha Lyle. 2009. Variation in stop consonant voicing in two regional varieties of American English. Journal of the International Phonetic Association 39(3). 313-334. https://dx.doi.org/10.1017\%2FS0025100309990156.

Jessen, Michael. 1998. Phonetics and phonology of tense and lax obstruents in German. Amsterdam: John Benjamins.

Kessinger, Rachel H. and Sheila E. Blumstein. 1997. Effects of speaking rate on voice-onset time in Thai, French, \& English. Journal of Phonetics 25, 143-168. https://doi.org/10.1006/jpho.1996.0039.

Kewley-Port, Diane. 1982. Measurement of formant transitions in naturally produced stop consonant-vowel syllables. Journal of the Acoustic Society of America 72. 379-389. https://doi.org/10.1121/1.388081.

Klatt, Dennis H. 1975. Voice onset time, frication, and aspiration in word-initial consonant clusters. Journal of Speech, Language, and Hearing Research 18. 686-706. https://www.ncbi.nlm.nih.gov/pubmed/1207100.

Liberman, Alvin M., Franklin S. Cooper, Donald P. Shankweiler, \& Michael Studdert-Kennedy. 1967. Perception of the speech code. Psychological Review 74. 431-461. https://doi.org/10.1037/h0020279.

Lisker, Leigh and Arthur S. Abramson. 1964. A cross-language study of voicing in initial stops: acoustical measurements. Word 20. 384-422. https://doi.org/10.1080/00437956.1964.11659830 
Lisker, Leigh and Arthur S. Abramson. 1970. The voicing dimension: Some experiments in comparative phonetics. Proceedings of the sixth international congress of Phonetic Sciences, Prague, 1967. http://www.haskins.yale.edu/SR/SR011/SR011_03.pdf.

Lorge, Beatrice. 1967. A study of the relationship between production and perception of initial and intervocalic /t/ and /d/ in individual English speaking adults. Haskins Labs Status Report Speech Research SR-9. 3.1-3.18. http://www.haskins.yale.edu/SR/SR009/SR009_03.pdf.

Magloire, Joël, and Kerry P. Green. 1999. A cross-language comparison of speaking rate effects on the production of voice onset time in English and Spanish. Phonetica 56. 158-185. https://doi.org/10.1159/000028449.

Miller, Joanne L., Kerry P. Green, and Adam Reeves. 1986. Speaking rate and segments: A look at the relation between speech production and speech perception for the voicing contrast. Phonetica 43, 106-115. https://doi.org/10.1159/000261764.

Pind, Jörgen. 1995. Speaking rate, voice-onset time, and quantity: The search for higher-order invariants for two Icelandic speech cues. Perception and Psychophysics 57. 291-304. https://doi.org/10.3758/BF03213055.

Ringen, Catherine and Vladimir Kulikov. 2012. Voicing in Russian stops: Cross-linguistic implications. Journal of Slavic Linguistics 20. 269-286. https://clas.uiowa.edu/sites/clas.uiowa.edu.linguistics/files/voicinginrussianstops.pdf.

Suomi, Kari. 1980. Voicing in English and Finnish stops: A typological comparison with an interlanguage study of the two languages in contact. Turku, Finland: University of Turku dissertation.

Van Alphen, Petra M., and Roel Smits. 2004. Acoustical and perceptual analysis of the voicing distinction in Dutch initial plosives: The role of prevoicing. Journal of Phonetics 32(4). 455491. https://doi.org/10.1016/j.wocn.2004.05.001.

Westbury, John R. 1979. Aspects of the temporal control of voicing in consonant clusters in English. Austin, TX: University of Texas dissertation.

Zue, Victor. 1976. Acoustic characteristics of stop consonants: A controlled study. Cambridge, MA: Massachusetts Institute of Technology dissertation. http://hdl.handle.net/1721.1/29469. 